\section{Lung cancer patients with small nodes on CT - what's the next step?}

\author{
J. T. Annema' ${ }^{1}$ K. F. Rabe ${ }^{1}$ \\ ${ }^{1}$ Division of Pulmonary Medicine, Leiden University Medical Center, \\ Leiden, The Netherlands
}

\section{Lung cancer patients with small nodes-background}

The management of patients with non-small cell lung cancer (NSCLC) without signs of mediastinal involvement (nodes < $1 \mathrm{~cm}$ short axis) at chest-computed tomography (CT) is subject of debate. Regarding the high prevalence of lung cancer and the fact that operable lung cancer patients often present with small nodes, the issue under investigation is very relevant. To date, these patients will rarely be referred for thoracotomy directly without further staging, as small nodes contain mediastinal metastases in around $18 \%$ (range $15 \%-37 \%$ ) of patients [1] and it is generally accepted that patients with locally advanced disease are preferable treated with multi modality treatment versus surgery alone [2,3]. For mediastinal staging, in addition to the well established surgical procedures mediastinoscopy-/tomy and thoracoscopy [4], novel methods have become clinically available such as Positron Emission Tomography (PET) and ultrasound- guided needle aspiration methods from both the esophagus (transesophageal ultrasound guided fine needle aspiration: EUS-FNA) and bronchi (endobronchial ultrasound guided transbronchial needle aspiration: EBUS-TBNA). Each of the staging methods has specific advantages and limitations and therefore various staging strategies are possible to accomplish accurate mediastinal staging. In this paper we will focus on patients with NSCLC and small nodes at chest CT and provide arguments for several different staging strategies for this large subset of patients.

\section{Staging methods}

EUS - FNA

Mediastinal nodes as small as $2-3 \mathrm{~mm}$ can be detected by EUS [5]. As EUS criteria alone have a moderate correlation for the presence or absence of metastases $[6,1,7]$ nodes with at least one ultrasound feature that is suggestive for malignancy - size short axis $>1 \mathrm{~cm}$, a round shape, sharp borders or a hypo-echoic appearance - should be biopsied. Nodes sized $<5 \mathrm{~mm}$ with a flat or oval shape and iso-echoic appearance (Fig.1) seldom contain metastases. Nodes as small as $4 \mathrm{~mm}$ can be aspirated under real-time ultrasound control in order to obtain tissue [5] (Fig. 2). Two prospective studies evaluated EUS-FNA in patients with NSCLC without enlarged nodes at chest CT. Wallace et al. reported that EUS-FNA demonstrated N2 - 3 lymph node metastases in 14 out of 67 patients ( $21 \%)$. There were also 9 false negative find-

Correspondence: Jouke Annema, MD, PhD · Department of Pulmonology C3 P . Albinusdreef 2 . PO box $9600 \cdot 2300$ RC Leiden - Leiden University Medical Center · Leiden · The Netherlands · Phone: 0031-71-5262950 - Fax: 0031-71$5266927 \cdot$ E-mail: j.t.annema@lumc.nl

Bibliography: Endoscopy 2006; 38 (S1): S77-S80 @ Georg Thieme Verlag KG Stuttgart · New York · ISSN 0013-726X · DOI 10.1055/s-2006-946661

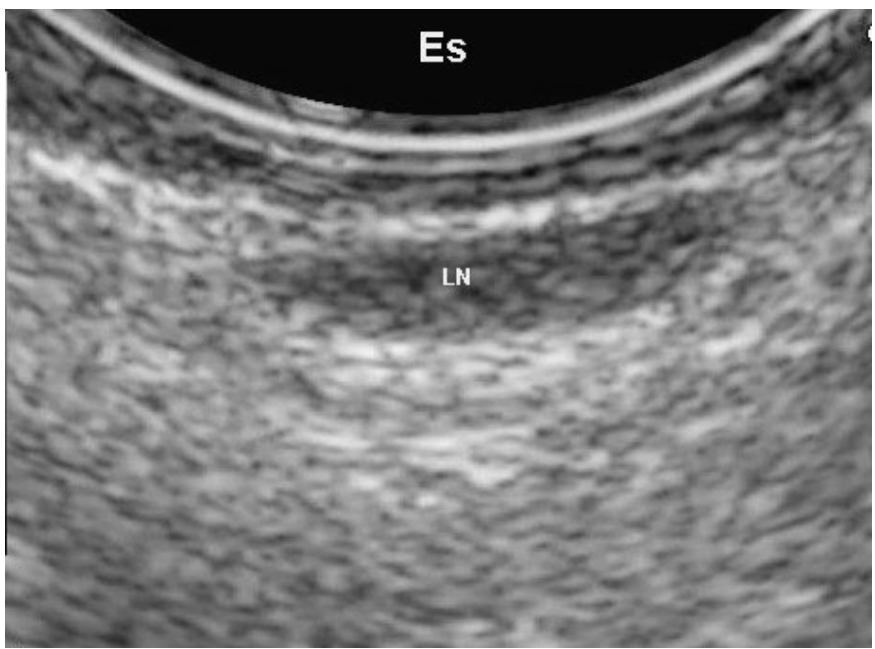

Fig. 1 Benign mediastinal node (LN), sized $3 \times 8 \mathrm{~mm}$, with a flat shape, an iso-echoic pattern and vague borders.

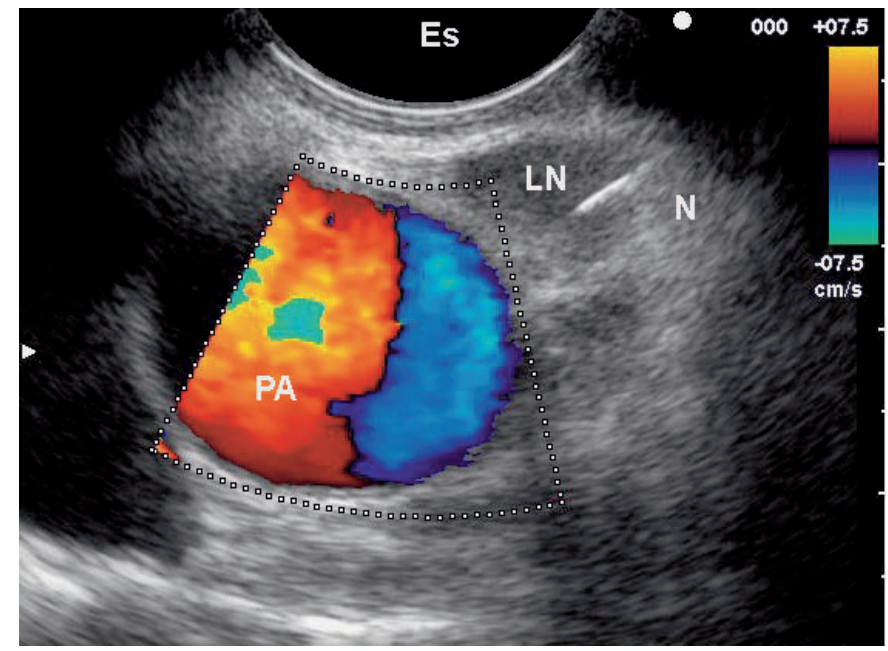

Fig. 2 EUS guided fine needle aspiration of an $8 \times 14 \mathrm{~mm}$ sized mediastinal node (LN), with a round shape, an hypo-echoic echo pattern and sharp borders located adjacent to the esophagus (ES) and the pulmonary artery (PA). ( $\mathrm{N}=$ Needle).

ings either due to sampling errors $(n=5)$ or the presence of metastases in pre-and para-tracheal lymph nodes that were not visible by EUS ( $\mathrm{n}=4$ ), resulting in a sensitivity of $61 \%$, a negative predictive value of $82 \%$ and an accuracy of $86 \%$. In addition to mediastinal metastases, EUS detected advanced disease in 3 more patients (4\%) by demonstrating tumour invasion (T4) $(n=2)$ or a left adrenal metastasis $(n=1)$. In summary, EUS demonstrated advanced disease (T4/ N2-3/M1) in 25\% of patients [8]. In this study, patients with subcarinal nodes sized up till $1,2 \mathrm{~cm}$ were included. In another EUS study for small nodes, Leblance and colleagues observed that EUS-FNA demonstrated N3 metastases in 5 of 67 patients (7\%). At surgical-pathological staging of the remaining 62 patients, mediastinal metastases were found in 17 more patients. The sensitivity, negative predictive value and accuracy of EUS-FNA in mediastinal staging were $23 \%, 73 \%$ and $73 \%$ respectively [9]. EUS precluded surgery in 9 patients (13\%), not only by the assessment of N3 nodes $(n=5)$ but also through the detection of metastatic celiac nodes $(\mathrm{n}=2)$, tumour invasion (T4) $(\mathrm{n}=1)$ and the detection of syn- 
chronous oesophageal cancer $(n=1)$. In 9 other patients, management was influenced by EUS, due the assessment of benign adrenal lesions $(\mathrm{n}=8)$ and a liver lesion $(\mathrm{n}=1)$. Overall, EUS findings changed patient management in $25 \%$ of cases. It should be noted that in this study, a radial EUS was performed first in all patients and only if a biopsy was indicated, patients underwent a linear EUS investigation. The prevalence of mediastinal metastases in these two studies - 35 and $36 \%$ respectively $[8,9]$ - is twice as high as expected [7] and, therefore, provides a bias towards the magnitude of the impact of EUS. The accuracy of EUSFNA of these two studies $[8,9]$ well below the reported values of $>90 \%$ obtained in patients with enlarged nodes [10-14]. These findings may be explained by the technical difficulty to sample small nodes or the limited presence of tumour cells in small metastases [8]. Both studies suggest that the site of the primary tumour - left upper lobe [8] or hilar and lower- lobe tumours [9] - is correlated with detecting metastases.

Summarizing, although data concerning EUS in patients with NSCLC and small nodes are still limited and need to be expanded, available results indicate that EUS can detect advanced disease in $12-25 \%$ of patients and results in a change of management in $25 \%$ of patients $[8,9]$. Besides the detection of $\mathrm{N} 2-3$ metastases, EUS is able to demonstrate advanced disease in patients with mediastinal tumour invasion (T4), left adrenal or celiac metastases (M1).

\section{(EBUS)-TBNA}

Transbronchial needle aspiration (TBNA) is a minimally invasive procedure to sample mediastinal nodes during bronchoscopy. The reported accuracy for TBNA varies widely and is highly depended on the prevalence of mediastinal metastases [15]. In a meta-analysis of studies with a median prevalence of mediastinal metastases of $34 \%$, the median sensitivity was $36 \%$ (range $32-38$ ) with a specificity of $98 \%$ (range $96-100$ ) [15]. The lack of proper visibility of the needle targeting a lesion is regarded as the main reason for the limited accuracy [16]. The very recent development of real-time EBUS-TBNA overcomes the problem of this "blind" procedure. Accuracies in mediastinal staging around 96\% have been reported in patients with enlarged hilar and mediastinal nodes $[17,18]$. To date, studies regarding EBUS-TBNA in small nodes are ongoing.

\section{Positron emission tomography}

PET has a pooled sensitivity of $84 \%(0.49-0.66 \%)$ and specificity of $89 \%(83-93 \%)$ for mediastinal staging and is more accurate than CT $57 \%(49-66 \%)$ and $82 \%(77-86 \%)$ respectively [1]. Accuracy of PET is dependent on lymph node size as shown in a recent meta analysis demonstrating that PET is more sensitive but less specific in patients with enlarged mediastinal nodes at CT [19]. In patients with both negative CT and PET findings, the post-test probability that these nodes contain metastases is $6 \%$ [19]. Another recent meta-analysis reported that in patients with a negative mediastinal PET and nodes sized $10-15 \mathrm{~mm}$, the post test probability for $\mathrm{N} 2$ disease was $5 \%$, whereas in nodes $>16 \mathrm{~mm}$ it was $21 \%$ [20]. Based on these findings, most clinicians refrain from further mediastinal staging in patients peripherally located tumours and nodes that are negative on PET and, less than $16 \mathrm{~mm}$. An advantage of PET is that it is a non-invasive test and it can detect occult distant metastases in up to $5-29 \%$ of ca- ses [21]. PET improves staging of lung cancer provided some rules are taken into account such as FDG uptake of the primary tumour, the use of dedicated PET equipment and the absence of hilar disease. In centrally located tumours, PET cannot differentiate accurately between the primary tumour and ipsilateral metastases due to its limited anatomical resolution [21]. Therefore, in patients with centrally located tumours, PET findings are usually not helpful for loco-regional staging. Obviously pathological confirmation is needed in the setting of PET positive mediastinal lesions due to its limited positive predictive value $[1,21,22]$.

\section{Surgical staging}

Mediastinoscopy has a sensitivity of $81 \%$ and specificity of $100 \%$ in analysing mediastinal nodes [7]. Although mediastinoscopy is accurate for those lymph node regions it can reach, it cannot reach part of the subcarinal region, the lower mediastinum and the aorto-pulmonary window. Thoracoscopy can reach lymph node levels beyond reach of mediastinoscopy $(5,6,8,9)$ and therefore the combination of mediastinoscopy and VATS can completely stage the mediastinum $[1,4]$.

\section{Discussion}

As accurate nodal staging is a prerequisite for optimal treatment planning, patients with non-small cell lung cancer and small nodes on chest $\mathrm{CT}$ require further evaluation. To date, there is no single staging method available that on its own provides accurate staging for all patients as each diagnostic test has its specific advantages and limitations. Obviously each additional test will increase the accuracy of nodal staging. In clinical practice, both the burden of the proposed staging strategy, costs, and patient preference should be taken into account, and the whole staging process should be performed within a limited time frame. In order to select a staging strategy, the post-test probability for unforeseen N2/N3 disease that is regarded to be acceptable, will ultimately govern this decision. Several arguments might play a role for the selection of a specific test(s). First of all, access to and experience with a method is required. To date, few hospitals have access to PET and EUS and EBUS, although further dissemination of PET-CT scanners and implementation of EUS/ EBUS technology is expected in the coming years. At an individual patient level, the location of the primary tumour might be a decisive factor for further patient management as the location of the primary tumour is associated with the site of regional metastases [23]. Left upper lobe tumours metastasize predominately to the stations 5, and left lower lobe tumours to station 7 and 9, regions accessible by EUS whereas right upper lobe tumours preferably drain to $4 \mathrm{R}$ [23], a region within the diagnostic range of mediastinoscopy and outside that of EUS. Also, it should be taken into account that node staging should not be regarded on its own but integrated in the whole concept on the assessment of both regional and distant metastases. In this discussion we will address various staging strategies for patients with NSCLC and small nodes on chest CT.

EUS-FNA might qualify as the method of choice in patients with small nodes as it has been demonstrated to assess advanced disease in up to $12-25 \%$ of patients $[8,9]$ and influence management in $25 \%$ of patients $[8,9]$. Patients with concomitant enlarg- 
ed left adrenal glands or suspected mediastinal tumour invasion (T4) might especially be appropriate candidates for EUS-FNA as it has been reported that EUS can assess or rule out left adrenal metastases [9,24] or mediastinal [25] and aortic [26] tumour invasion (T4). However, provided EUS does not asses regional or distant metastases, further staging is required as the negative predictive value of EUS in patients with small nodes was only $73-82 \%[8,9]$. EUS could be followed by mediastinoscopy as both methods are complimentary in their diagnostic range [2729] or PET. As EUS and EBUS are complementary in their diagnostic reach combined staging by both endoscopic methods has also been suggested $[30,31]$.

Positron emission tomography seems a logical choice for staging of patients with peripherally located tumours, as it is non-invasive and the likelihood of unforeseen mediastinal metastases in patients with both a negative CT and PET scan is around 5\% $[19,20]$. It is generally accepted that these patients can be referred for thoracotomy and tumour resection without undergoing further staging tests [21]. An additional advantage of PET is the detection of unforeseen occult metastases [21]. It should be noted however that for accurate nodal staging for all patients with either mediastinal involvement at FDG-PET or a centrally located tumour, tissue has to be obtained [21]. Analysing PET positive lesions by EUS has been shown to be a minimally, accurate and cost effective staging strategy [32-34]. In the only comparison study between CT, PET and EUS-FNA, with detection of inoperable patients as the primary outcome, a slightly improved sensitivity and comparable specificity for EUS-FNA vs combined CTPET findings was reported ( 94 vs $81 \%$ ) and (100 vs $94 \%$ ) [35].

The position of mediastinoscopy as the initial staging method for NSCLC is subject of debate with the increasing availability of non- and minimally invasive methods such as PET, EUS- and EBUS-TBNA [36]. EUS-FNA and mediastinoscopy are complementary in their diagnostic range [27 - 29] and combined staging improves the selection of patients for surgery [27] and prevents futile thoracotomies [29]. In a hospital setting without access to PET it is logical to perform both EUS and mediastinoscopy, starting with the least invasive test (EUS). As the diagnostic range of EBUS-TBNA overlaps with that of mediastinoscopy, it is expected that the number of mediastinoscopies will further decline in favour of EBUS that is minimally invasive and does not require general anaesthesia non admission to he hospital. However, as long as EBUS has not been proven to have a similar or increased accuracy for mediastinal staging in small nodes compared to mediastinoscopy, mediastinoscopy is expected to be an important staging method for the coming years.

In summary, for accurate mediastinal evaluation of NSCLC patients with small nodes at chest CT further staging is needed. The choice of the additional staging test(s) will depend on the access to novel methods, experience with specific techniques and patient related factors such as the localisation of the primary tumour. Either PET and/ or EUS-FNA qualifies best as the initial diagnostic procedure, whereas EBUS-TBNA is a third promising alternative. The role of mediastinoscopy remains important as a second procedure after negative $\mathrm{E}(\mathrm{B}) \mathrm{US}$ findings and in those hospitals without access to either PET or E(B)US. Further studies are urgently needed in order to define an optimal staging strate- gy for this large subset of patients with non-small cell lung cancer and small nodes.

\section{References}

1 Toloza EM, Harpole L, McCrory DC. Noninvasive staging of non-small cell lung cancer: a review of the current evidence. Chest 2003 Jan; 123 (1 Suppl):137S -146S 2003; 123: 137S-146S

2 Spira A, Ettinger DS. Multidisciplinary management of lung cancer. $\mathrm{N}$ Engl J Med 2004; 350 (4): 79-392

${ }^{3}$ Spiro SG, Porter JC. Lung cancer - where are we today? Current advances in staging and nonsurgical treatment. Am J Respir Crit Care Med 2002; 166 (9): 1166 - 1196

${ }^{4}$ Passlick B. Initial surgical staging of lung cancer. Lung Cancer 2003; 42 Suppl 1: 21S-25S

${ }^{5}$ Vilmann P. Endoscopic ultrasonography-guided fine-needle aspiration biopsy of lymph nodes. Gastrointest Endosc 1996; 43: 24S-29S

${ }^{6}$ Schmulewitz N, Wildi SM, Varadarajulu S, Roberts S, Hawes RH, Hoffman BJ et al. Accuracy of EUS criteria and primary tumor site for identification of mediastinal lymph node metastasis from non-small-cell lung cancer. Gastrointest Endosc 2004 Feb ;59 (2):205 - 12 2004; 59: $205-212$

${ }^{7}$ Toloza EM, Harpole L, Detterbeck F, McCrory DC. Invasive staging of non-small cell lung cancer: a review of the current evidence. Chest 2003 Jan; 123 (1 Suppl):157S-166S 2003; 123: 157S - 166S

${ }^{8}$ Wallace MB, Ravenel J, Block MI, Fraig M, Silvestri G, Wildi S et al. Endoscopic ultrasound in lung cancer patients with a normal mediastinum on computed tomography. Ann Thorac Surg 2004; 77 (5): 1763 1768

${ }^{9}$ Leblanc JK, Devereaux BM, Imperiale TF, Kesler K, Dewitt JM, Cummings $\mathrm{O}$ et al. Endoscopic Ultrasound in Non-Small Cell Lung Cancer and Negative Mediastinum on Computed Tomography. Am J Respir Crit Care Med, 2004

${ }^{10}$ Annema JT, Versteegh MI, Veselic M, Voigt P, Rabe KF. Endoscopic ultrasound-guided fine-needle aspiration in the diagnosis and staging of lung cancer and its impact on surgical staging. J Clin Oncol 2005; 23 (33): $8357-8361$

${ }^{11}$ Fritscher-Ravens A, Sriram PV, Bobrowski C, Pforte A, Topalidis T, Krause $C$ et al. Mediastinal lymphadenopathy in patients with or without previous malignancy: EUS-FNA-based differential cytodiagnosis in 153 patients. Am J Gastroenterol 2000; 95 (9): 2278 - 84 2000; 95: $2278-2284$

12 Larsen SS, Krasnik M, Vilmann P, Jacobsen GK, Pedersen JH, Faurschou $P$ et al. Endoscopic ultrasound guided biopsy of mediastinal lesions has a major impact on patient management. Thorax 2002; 57 (2): 98-103 2002; 57: 98 - 103

${ }^{13}$ Wallace MB, Silvestri GA, Sahai AV, Hawes RH, Hoffman BJ, Durkalski V et al. Endoscopic ultrasound-guided fine needle aspiration for staging patients with carcinoma of the lung. Ann Thorac Surg 2001; 72 (6): $1861-1867$

${ }^{14}$ Williams DB, Sahai AV, Aabakken L, Penman ID, Van Velse A, Webb J et al. Endoscopic ultrasound guided fine needle aspiration biopsy: a large single centre experience. Gut 1999; 44: 720-726

${ }^{15}$ Holty JE, Kuschner WG, Gould MK. Accuracy of transbronchial needle aspiration for mediastinal staging of non-small cell lung cancer: a meta-analysis. Thorax 2005; 60 (11): 949 - 955

${ }^{16}$ Wang KP. Continued efforts to improve the sensitivity of transbronchial needle aspiration. Chest 1998; 114 (1): 4-5

${ }^{17}$ Yasufuku K, Chiyo M, Sekine Y, Chhajed PN, Shibuya K, Iizasa T et al. Real-time endobronchial ultrasound-guided transbronchial needle aspiration of mediastinal and hilar lymph nodes. Chest 2004; 126 (1): $122-128$

18 Yasufuku K, Chiyo M, Koh E, Moriya Y, Iyoda A, Sekine Y et al. Endobronchial ultrasound guided transbronchial needle aspiration for staging of lung cancer. Lung Cancer 2005; 50 (3): 347-354

19 Gould MK, Kuschner WG, Rydzak CE, Maclean CC, Demas AN, Shigemitsu $\mathrm{H}$ et al. Test performance of positron emission tomography and computed tomography for mediastinal staging in patients with nonsmall-cell lung cancer: a meta-analysis. Ann Intern Med 2003; 2;139 (11): $879-892$ 
${ }^{20}$ de Langen AJ, Raijmakers P, Riphagen I, Paul MA, Hoekstra OS. The size of mediastinal lymph nodes and its relation with metastatic involvement: a meta-analysis. Eur J Cardiothorac Surg 2006; 29 (1): 26 - 29

${ }^{21}$ Vansteenkiste JF. PET scan in the staging of non-small cell lung cancer. Lung Cancer 2003; 42 Suppl 1: 27S-37S

22 Silvestri GA, Tanoue LT, Margolis ML, Barker J, Detterbeck F. The noninvasive staging of non-small cell lung cancer: the guidelines. Chest 2003; 123 (1 Suppl): 147S - 156S

${ }^{23}$ Kotoulas CS, Foroulis CN, Kostikas K, Konstantinou M, Kalkandi P, Dimadi $\mathrm{M}$ et al. Involvement of lymphatic metastatic spread in nonsmall cell lung cancer accordingly to the primary cancer location. Lung Cancer 2004; 44 (2): 183-191

${ }^{24}$ Eloubeidi MA, Seewald S, Tamhane A, Brand B, Chen VK, Yasuda I et al. EUS-guided FNA of the left adrenal gland in patients with thoracic or GI malignancies. Gastrointest Endosc 2004; 59 (6): 627-633

${ }^{25}$ Varadarajulu S, Schmulewitz N, Wildi SF, Roberts S, Ravenel J, Reed CE et al. Accuracy of EUS in staging of T4 lung cancer. Gastrointest Endosc 2004; 59 (3): 345 - 348

${ }^{26}$ Schroder C, Schonhofer B, Vogel B. Transesophageal echographic determination of aortic invasion by lung cancer. Chest 2005; 127 (2): $438-442$

${ }^{27}$ Annema JT, Versteegh MI, Veselic M, Welker L, Mauad T, Sont JK et al. Endoscopic ultrasound added to mediastinoscopy for preoperative staging of patients with lung cancer. JAMA 2005; 294 (8): 931 -936

${ }^{28}$ Eloubeidi MA, Tamhane A, Chen VK, Cerfolio RJ. Endoscopic ultrasound-guided fine-needle aspiration in patients with non-small cell lung cancer and prior negative mediastinoscopy. Ann Thorac Surg 2005; 80 (4): 1231 - 1239

${ }^{29}$ Larsen SS, Vilmann P, Krasnik M, Dirksen A, Clementsen P, Maltbaek N et al. Endoscopic ultrasound guided biopsy performed routinely in lung cancer staging spares futile thoracotomies: preliminary results from a randomised clinical trial. Lung Cancer 2005; 49 (3): 377-385

${ }^{30}$ Rintoul RC, Skwarski KM, Murchison JT, Hill A, Walker WS, Penman ID. Endoscopic and endobronchial ultrasound real-time fine-needle aspiration for staging of the mediastinum in lung cancer. Chest 2004; 126 (6): $2020-2022$

31 Vilmann P, Krasnik M, Larsen SS, Jacobsen GK, Clementsen P. Transesophageal endoscopic ultrasound-guided fine-needle aspiration (EUSFNA) and endobronchial ultrasound-guided transbronchial needle aspiration (EBUS-TBNA) biopsy: a combined approach in the evaluation of mediastinal lesions. Endoscopy 2005; 37 (9): 833 - 839

${ }^{32}$ Annema JT, Hoekstra OS, Smit EF, Veselic M, Versteegh MI, Rabe KF. Towards a minimally invasive staging strategy in NSCLC: analysis of PET positive mediastinal lesions by EUS-FNA. Lung Cancer 2004; 44 (1): $53-60$

33 Eloubeidi MA, Cerfolio RJ, Chen VK, Desmond R, Syed S, Ojha B. Endoscopic ultrasound-guided fine needle aspiration of mediastinal lymph node in patients with suspected lung cancer after positron emission tomography and computed tomography scans. Ann Thorac Surg 2005; 79 (1): $263-268$

${ }^{34}$ Kramer H, van Putten JW, Post WJ, van Dullemen HM, Bongaerts AH, Pruim J et al. Oesophageal endoscopic ultrasound with fine needle aspiration improves and simplifies the staging of lung cancer. Thorax 2004; 59 (7): $596-601$

${ }^{35}$ Fritscher-Ravens A, Bohuslavizki KH, Brandt L, Bobrowski C, Lund C, Knofel WT et al. Mediastinal lymph node involvement in potentially resectable lung cancer: comparison of $\mathrm{CT}$, positron emission tomography, and endoscopic ultrasonography with and without fine-needle aspiration. Chest 2003; 123 (2): 442-451

${ }^{36}$ Rusch VW. Mediastinoscopy: an endangered species? J Clin Oncol 2005; 23: $8283-8285$ 